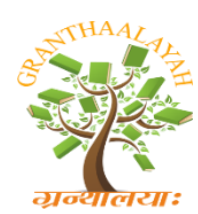

INTERNATIONAL JOURNAL OF RESEARCH GRANTHAALAYAH

A knowledge Repository

Management

\title{
IMPACT OF PEER PRESSURE ON BUYING BEHAVIOUR
}

\author{
Shruti Gulati *1 \\ ${ }^{* 1}$ Guest Faculty, Department of Commerce, Shaheed Bhagat Singh College, University of Delhi, \\ India \\ DOI: https://doi.org/10.29121/granthaalayah.v5.i6.2017.2027
}

\begin{abstract}
Purchase of a commodity, good or service is guided by a host of factors. Each factor influences a purchase differently. While some stimulate buying, the other might discourage a consumer. Peer pressure is one of those unique pushes that a rational consumer considers before an actual or a potential purchase of any good or service. Peer pressure rightly puts pressure of the peer or the persons surrounding for any action, buying being the relevant one in this case.

Keywords: Peer Pressure; Buying; Influence; Spending; Goods; Teenager.

Cite This Article: Shruti Gulati. (2017). "IMPACT OF PEER PRESSURE ON BUYING BEHAVIOUR." International Journal of Research - Granthaalayah, 5(6), 280-291. https://doi.org/10.29121/granthaalayah.v5.16.2017.2027.
\end{abstract}

\section{Introduction}

"Monkey see, monkey buy."

- Harvard Business Review

Peer pressure can be said as a social phenomenon where a pressure is exerted by members of a society and a social group which influence on a person's behaviour though not always negative but majorly towards socially undesirable behaviour such as the ones where people are resistant or not much inclined to do.

Younger lot such as teenagers and adolescents are more vulnerable to peer pressure because of the age where being gullible is more than expected because the mind hasn't matured properly and is still in the development stage.

Knowing or unknowingly peers tend to influence one's life. This is because of the time spent with them. Peer pressure can also be said as a continuous learning having a positive, negative or normative impact on an individual. Peer pressure is often guided by an approach of "what everyone is doing" or out of general curiosity or maybe by a motive of being in the league as 
others. Peer pressure in buying can be seen when we see friends shopping together at malls or when activities such as smoking and alcohol are increasing. It not only affects the actual purchase but also influences the attitude such as retailing and spending capacities of teens.

\section{Objectives}

- Understand the meaning of peer pressure

- Overview of impact of peer pressure in purchase

- Analysis of effects of peer pressure in buying behaviour

- Highlighting the Indian scenarios

\section{Research Methodology}

This paper consists of the conceptual analysis related to the topic: "IMPACT OF PEER PRESSURE ON BUYING BEHAVIOUR". The research paper is an attempt of Descriptive Research, based on the secondary data sourced from various newspaper articles, journals, magazines, press releases and media reports.

\section{Meaning of Peer Pressure}

Peer pressure is the direct or indirect influence that is exerted on a peer group, observers or individual that encourages others to change their attitudes, values, or behaviors to conform to groups as a socially acceptable behavior under it. Social groups affected include membership groups, in which individuals are formally involved and are members like that of political parties and trade unions, or social cliques in which membership is not clearly defined. A person affected by peer pressure may or may not want to belong to these groups on his personal discretion but tends to get influenced. They may also recognize dissociative groups with which they would not wish to associate, and thus they behave adversely concerning that group's behaviors.

Some kids give in to peer pressure because they want to be liked, to fit in, or because they worry that other kids may make fun of them if they do not go along with the group. Others may go along because they are curious to try something new that others are doing. The idea that "everyone is doing it" may influence some kids to ignore their better judgment or their common sense. Peer pressure can be extremely strong and seductive. Experiments have shown how peer pressure can influence children to change their minds from what they know for sure is acceptable behavior to unacceptable behavior just because everyone else in their peer group is doing it. These studies have also shown that all it takes for individuals to stand their ground on what they know is right is for one other peer to join them. That principle holds true for youth of any age in peer pressure situations, according to the online organization KidsHealth (http://www.kidshealth.org ).

The way pressure is applied by peers can vary and can be extremely subjective. A peer might impose pressure directly by asking to do something, this shall be direct or to tease or coax the person, so as to make the person's behavior fall in line with their but the latter one can be followed by the big bullies. They may not say anything at all; instead, they may pressurize by 
giving a treatment like that of an outcast or by simply ignoring. This is aimed at hurting the ego and breaking self-esteem.

Peer pressure has become a hallmark experience in the youth for it is assumed to be as mandatory as living the age itself. Peer conformity in youth can be seen with respect to style, taste, appearance, ideology and values. It can be taken as adolescence risk taking such as drug abuse, smoking and is portrayed to be the predictor of one's own behavior.

While the most common notion of peer pressure is relating to negative or socially undesirable effects such as bad company pushing into alcohol, smoking etc. there is also scope for positive impact of the peer influence. Good company can also drive benefits from peers such as academic excellence, charity and hospitability etc.

Peer pressure can also inculcate a competitiveness with its fellow peers for indulging in extracurricular activities such as sports, dance, drama etc.

\section{Perception of Peer Pressure}

"Pressure has the power to create a diamond, but it has to be the "right" pressure."

- Shannon L. Alder

It is most common to judge the impact of peer pressure as having a negative influence and hence making in mind a negative perception of it, but in rare cases there are impacts other than negativity of the influence of peers on a person's behavior that have a positive bearing on an individual or group. While most likely having a negative perception about this pressure makes people run away from peer pressure and they shy away in fear of being carried away with activities such as smoking, sex, drug abuse etc. People tend to believe that it shall induce them in things that they would not want to do in the normal course of action, and they shall indefinitely be carried away by such a pressure. But this is not the only side of the coin. There can be effects which might not be easily differentiated from being positive or negative like that of Fashion. The new generation is more inclined towards carrying off the trend to be in vogue. Lifestyles are changing from domestic to corporate to an extent that the new era houses are also designed like that of offices. Beautification has become another concern now a days. Everybody wants to be fit and look better than others. This has led to a recent phenomenon of diets, gyms and organic foods. In the race of being at par if not superior, the individual is no doubt affected but not always as positive or negative. There is no question over certain influences having plain positive and magical impacts too. When a friend stops or gives the right advice about how alcohol intoxicates the body, or how cigarettes damage the liver, it is a positive impact of peer pressure even if adversely affecting the marketers of tobacco manufacturers. This might be rare and hence the perception shall always majorly continue to be negative when it comes to peer pressure.

Peer pressure can result in a loss of individuality where following the lead blindly. Extreme peer pressure might direct towards following of what the peers feel right irrespective of the true rightness of a situation. Peer's pressure may compel a person to go by everything they think right. Tendency might be to blindly imitate the masses; adopting their tastes of fashion, clothing, hair, music and general living. Peer pressure can actually lead to losses relating to tastes of life 
and forcing to begin liking what others like. Peer pressure is the human tendency to not only look but also join the bandwagon, in which, the person loses his/her original way of looking at life.

At the same time Peer pressure is not always bad. It can help analyze oneself and contemplate on the ways of life. Some of the practices that the masses follow may actually teach the way of living and its betterment. Looking at what others do, can help bring about a positive change in way of thinking. This requires selectivity, which can result in a positive change in the life of an individual.

Knowing what the masses follow gives exposure of the outside world, an understanding of the things going on around. An exposure to a wide variety in human behavior; exposure to peer pressure gives an opportunity to think about peer's tastes and their outlooks towards life. It gives an individual or group a chance to choose the best from what the masses do and hence become the best.

Fortunately some good peer groups, play a vital role in the shaping the personality. The way of looking at life may influence you to change for betterment. Some of peers such as close friends, who do not pressurize to do things but rather inspire to change yourself, persuade to bring about a constructive changes in personality. Hence Peer pressure can lead to make the right choices in life, thus can have a positive impact which might enable to change the perception towards being positive as well.

When it comes to buying and consumer behavior, it is always perceived that good or bad, the peer pressure imposes an impact which is in the best use of marketers. Where trendy things like Selfie Sticks or branded products such as iPhones, Androids all are getting companies a world time high of sales. Be it commodities inducing addiction, or sexual behavior there is no loss to the enterprises at all. Marketers are neutral to the fact if the perception about peer pressure is positive or not unless, to save their Corporate Image or inculcating Corporate Social Responsibilities.

Shopping with friends, or clubbing all shall majorly induce excessive buying and hence shall bring prosperity to the manufacturers. Where on one side academic excellence may push towards demand of coaching centers, books and study material on the other hand the decision regarding having high class friends or boyfriends shall indicate higher demand of branded commodities for consumption or gifting. What so ever might be the reasoning with whatever perception in mind, the corporates turn victorious.

Teens influenced by peer pressure purchase what friends buy, product branding and marketing give adolescents a way to quickly identify items and Branding involves placing a manufacturing logo prominently on goods.. - American Psychological Association,

The APA claims teen groups pay attention to products, and seek out branded products as a way to have immediate prestige with friends. Companies also target teens in print, store promotions, online and television advertisements. 


\section{Impact of Peer Pressure in Purchase}

Stuart Roper and Binita Shah from the Manchester Business School at University of Manchester have explained their point about how "Brands can be the cause of social division amongst children resulting in the formation of "in" groups and "out" groups. There is a fear of discrimination by the ones not buying the right or fancy brands that match their peer's and shall experience social impacts which such as teasing, bullying, lower self esteem or even an extent of social exclusion. The impact of this cannot just be seen on the children but also their parents who face guilt and are being pestered for such purchases, and struggle to provide enough financial incentives to support such demands.

It can be witnessed that Peer Pressure has a chain reaction starting from the child, moving towards pressure on parents and eventually ending with a purchase to prove that the pressure was successful in eventually making the purchase happen. This is the reason why marketers exploit peer pressure opportunities.

(http://www.123helpme.com/peer-pressure-and-consumer-behavior-view.asp?id=166811)

Recent research suggests that mothers tend to take their children on a "co-shopping" experience giving their children a greater input and freedom into the household shopping which includes their favorite biscuits, cereals, lollipops etc.

Teenagers and youngsters are usually vulnerable to peer pressure and have high tendency to make decisions and develop behaviours which positively comply with the peer's expectations. For a study conducted in Botswana researchers found that the impact of peer pressure on purchase intention is quite significant, being more strongly and positively related to publicly consumed goods than the privately consumed goods (Mokgosa \& Mohube, 2007). The young customer behaviours are manipulated by peer pressure as they feel it as an essential aspect to fitin their social group is aligned with the acceptability level and cope with the trends and life of their peers. (Kao \& Zhang, n.d.) (http://core.ac.uk/download/pdf/26201995.pdf )

"Peer smoking was by far the strongest predictor of smoking progression," said Elizabeth LloydRichardson of Brown University in Providence, R.I. It was seen that not just the impact of friends was affecting youngsters to smoke but also the sight or knowledge of their parents indulging the same. Lloyd Richardson also quoted "Teens that are already experimenting with smoking, are drinking alcohol, and have friends who smoke regularly should be targeted with interventions that halt the entrenchment of smoking," (Journal of Clinical and Consulting Psychology)

Peer pressure, or the direct or indirect encouragement from one's own age group to engage in activities that they may or may not want to engage in (Santor, Messervey, \& Kusumakar, 2000), is a major factor in the development of risk-taking behaviours (e.g., alcohol use, drug use, and tobacco use; (Lewis \& Lewis, 1984). Peers act as an influential model by introducing, providing, or pressuring risky activities (i.e., alcohol use) to other peers (Kinard \& Webster, 2010). By modelling these behaviours to their peers, college students are viewing alcohol use as a positive and socially acceptable experience (Kinard \& Webster, 2011). However, what college students 
fail to take into consideration are the negative consequences that are related to alcohol use, especially within a peer group context.

(http://steinhardt.nyu.edu/opus/issues/2011/fall/peer )

This is leading to a blooming industry of breweries and tobacco. The present generation of children are carried away with the tide of peer pressure for such consumption, irrespective of rational notions of good or bad. The winners of all time are the manufacturer, distributors and marketers who experience a sky high sales level.

\section{Low Peer Pressure Immunity}

"Everyone would like to believe that they are immune to outside influences, but studies find that surroundings play a key role in the decision making."

One of the most telling studies done on peer pressure was conducted in the 1950s by Social Psychologist Solomon Asch. In the experiment, participants were shown a line and then asked to choose which line (out of three) matched the original. When in a group with confederates (or participants savvy to the true purpose of the experiment) who chose the visibly longer line as opposed to the true match, almost 75 percent of participants followed suit. (https://www.qualvu.com/asynchronous-video-research/9403/)

This clearly lays down the truth behind purchase behaviour of individuals or group while making a purchase decision, or rather it is the universal truth relating to all forms of influence that peer pressure exerts. The major areas where low resistance and immunity to such pressure can be seen are:

- Cigarettes

Ignoring the Health concerns, it's sad to know how cigarettes still continue to be a trend which soon converts into addiction. Despite Government's repeated initiatives of preventing smoking by issuing warning on the package, setting the minimum age limit and the like, peer pressure has pushed a major proportion of youth into smoking not leaving a doubt about the flourishing business of the Tobacco industry in the world.

- Alcohol

Barring or not barring the legal age of drinking, alcohol consumption has become a vital area of concern where peer pressure is concerned. Where youth is involved in forceful consumption at social gatherings to not feel left out of their peer gang, adults aren't lagging behind either. On being asked about the fact of relishing flavour of alcohol there shall be rare cases of positive reactions but at the same time questioning the intake there shall be major response of being positive. The reason behind why people consume alcohol and get intoxicated even when they aren't even fond of it is peer pressure. Not having a glass at night parties has become socially awkward and backward. In trying to prove the narrowness of mind set endless people are stuffing themselves into being from occasional, to casual, to habitual drinkers.

- Drugs

The strongest predictors of drug use during adolescence is peer pressure. It is usually observed that peers initiate youth into drugs, provide drugs, model drug-using behaviours, and shape attitudes about drugs, they are the ones to begin the chapter of drug abuse into the life of their 
own very acquaintances. To feel good and secure themselves, peers trap others as partners in crime in the whole vicious circle of drug addiction.

- Technological gadgets

Technological gadgets are the new toys to the present generation. Having seen a friends with one, the non-possession almost seems inferior. Tablets, mobile phones, laptops, play station are the modern era measures to check the worthiness into a specific peer group. Companies such as Samsung, HTC, Lenovo, Dell are cashing on such opportunities. Not just the possession but the holding of the latest model is equally important to display your social class. Having a Blackberry once was considered an essential is now treated as outdated. Even children are hesitant to own that over maybe a not so known Android model.

- Apple Products

Visualizing the famous advertisement from Apple Inc. relating to their iPhones "If you don't have an iPhone, you don't have an iPhone" for their flagship model iPhone 4 has almost set a bar for the technological sector it operates. The impact can be seen more on youth as it has been considered as an ultimate means of showing off the financial capabilities of spending huge amount on gadgets. 'Cool' as it may be called to describe its products. Apple has conquered market like no other having products such as MacBook iPhone, iPad, iPod and now Apple TV and Apple Watch. Their marketers specifically aim at such campaigns and advertisements that infuse within the person a strong desire to invest in that product. Students ranging from primary to secondary grade look forward to Apple products to judge the richness of background of their peers. To think about it, it's not just the ownership but about how early the possession over the product can be done. The craze is such that people during its first day release stand in huge queues and are even willing to pay a premium to get it earliest. Everyone wishes to buy it to be in that league of peer group. On a survey, most fresh graduates wish to buy an iPhone/MacBook for it is now considered a luxury that they wish to possess once they start earning. For Apple, peer pressure has been not just a driving force for $\mathrm{s}$ single purchase but it multiplies and diversifies into other products as rightly the users say 'once an apple user, always an apple user.' As trends suggests, this soon leads to brand loyalty and an ensured repeat purchase to stay in tune with the Apple User league.

- Automobiles and other vehicles.

The old fashioned symbol of wealthy through automobile ownership has been continuing since decades. Else a noticeable feature in the present day trends is that people wish to buy cars that define them with industrialists sticking to posh models or environmentalists going with hybrid mechanisms. Ranging from the giants of all time; Mercedes and BMW series or the German entrant Audi or the sports cars by Ferrari, have been on the hit list of all age group individuals so as to own/buy the latest model in comparison to their peers. Similarly motorbikes and sports bikes like that of Harley Davidson, Kawasaki Ninja and Suzuki Hayabusa have been a demand of the rich spoilt brats. Not just conventional bikes and cars, peer pressure is inducing individuals to indulge in buying nonconventional vehicles such as Vintage Cars, high end bicycles such as that of Mercedes Benz (costing INR 3.5Lacs)

\section{Effects of Peer Pressure on Purchase Decision}

The effect of peer pressure on purchase decision is not directly proportional where a positive peer pressure may necessarily mean a positive purchasing decision or a negative peer pressure shall always lead to a negative purchase decision. 
Peer pressure is always going to lead to purchasing; which product, shall be a question to be well answered. Endless products in the market can easily substitute each other.

For example: Peer pressure has urged people's desire to look good and fit that too better than others. This has led to more and more people becoming part of the yoga, gym and diet league. People are demanding organic, low fat and healthier products. Gyms are running business on a life time high. Self-conscious efforts can be seen by demands of healthier products such as Protein Shakes, Nutrient Bars; whole wheat products has been a constant. Looking good and chic has become quite an expensive habit. This has resulted into FMCG brands with diversification such as Nestle Maggi to come up with Oats Maggi, or Safola with Masala Oats. Demand is met and hence there is a purchase, completing the circle. Purchase of fitness ancillaries such as dumbbells, yoga mats is also side by side increasing with the health concerning issues. Also light oils such as Olive Oils from Spain are being exported for Indian customers to purchase. Marketing as rightly said is meeting the customer need at the right time and the right way. Hence, they benefit the most. Manufacturers are able to occupy maximum market share and greatest customer value.

Similarly where negative peer pressure induces alcohol, tobacco and drug consumption; positive peer pressure leads to moving away from these products. Some peers motivate their fellow peers to get rid of such addictions. Various products such as chewing gums by Kwik Nik, Nicotex and Nicorette etc. or e-cigarettes also are being purchased frequently. Friends and family member are relying on these products for helping reduce smoking and drinking amongst peers. Hence, Positive peer pressure can also lead to increased purchases.

Basically either purchasers will substitute their purchase or the existing manufacturers or marketers will mend their products to ensure there is no decline in sales.

Peer pressure is most likely to be experienced for 'public luxuries' such as branded fashion items-(Childers and Rao, 1992)

Peer pressure has given rise to brand consciousness amongst people from all age groups and classes. Brands may vary from products to incomes. From gadgets such as XBOX, PlayStations to fashionable clothes, accessories etc. It is believed that products might be manufactured in a factory but the image is made in the mind. Subconsciously an illusion of a thing before it is presented is created. This image creates a level out in the front of which the comparison is made for superiority. The pressure to reach a stage of possessing the superior one is guided by peer pressure. The difference amongst brands might be miniscule. But that's not the point of concern, the brand mark is. The material of a T-Shirt bearing a crocodile or three stripes might not be very different but from the point of a brand conscious person it shall be. Lacoste is a luxury clothing brand whereas Adidas a sports brand. People try to purchase products and brands that suit them, their image and their class and hence the brand wars. Youth is more focussed on trendy fashionable branded clothes whereas established independent individuals shall widen their brand purchases for products such as watches like Rolex, Omega, Rado or bags from Louis Vuitton, Burberry or eyewear from Ray Ban, Armani etc. All in all fashion products are going to turn eye balls and people are pressurised to make that happen, because of an emotion attached to it. It's all about that label and the imagery it creates. 
It is usually noticed that teenagers tend to purchase more on movie tickets as they love going out with their peer groups or go on events that are hyped about or have a lot of peer excitement. This has gained more importance due to various features of social media websites such as Facebook, Four Square etc. through which people can 'check-in' at the place visited. Outings have become a proclamation to the world. Passes of events such as Formula1, Weekender, and Sunburn etc. receive mass prebooking and people even purchase them at a premium or in black. More than the enjoyment, a show off of the event is highlighted through sharing of videos via Twitter, Instagram etc. because everyone wishes to be in the 'cool' gang.

With the present technological improvements and emergence of ecommerce, the first thought which comes to the mind is browsing through the customer reviews and recommendation despite knowing that many of them are fake. The mental satisfaction that others have bothered to pen down their views on the product seems more vital self-judgement over it. At that point of time, other's opinion rule over personal choices.

"We like to think that we are independent souls, that we are in control of our own actions, but what his study showed was that the power of conformity, the power of suggestion, all of these influences that we think don't affect us that much, really are important," -Guo

Also, when accompanied by friends people are seen to be more brand conscious and spend thrift. They want people to perceive a social image of them greater than the actual. Hence they shall exceed the planned budget and shop in excess because subconsciously in the mind they are conscious about their image as their shopping shall define and create. This phenomenon can also be seen while dining out. While going out with family and friends, the attitude towards spending changes. Fine dines are chosen for having food, similarly valet parking also doesn't pinch much because it's all about creating the right image and not being less than anyone.

\section{The Indian Scenario}

In India, society plays a major role for existence. Since birth, Indians indulge in activities that are socially acceptable. The definition of society might differ from person to person, and so shall the constituents of it. For teenagers the most important acceptance is by peers, while they grow up the pressure of conforming to social norms shifts towards social etiquettes and continue to impact the individual. Inspired by the western culture, Indian households also encounter parents catching hold of their barely teenage children indulging in drinking and smoking. To this most children consider it 'not a big deal' and an attempt of not being prude or boring. Indian parents stereotypically can't withstand such acts by their children and expect them to not be dictated blindly by peers.

Teenagers are inquisitive and excited with the new found independence in their teens with pocket money or monthly allowances. They are purchasing without giving much thought to the utility or worth.

Similarly peer pressure guides the relationship with the opposite sex. Dating during schooling and college has become like a 'must' experience. Also following the western trend every second day has become a celebration. Days such as Friendship Day, Valentine's Day, Father's Day and 
Mother's Day have occupied importance in India too. Emotionally these days have started having their own meaning and place especially amongst youth. During school days everyone has seen the enthusiasm for Friendship Day where giving and receiving the best friendship band was quite a big thing. Endless friendship bands from gift shops such as Archies, Hallmark etc. were purchased so that they could be showed off amongst their peer group. Similarly Valentine's Week carries a lot of buzz about gifting of chocolates, roses and teddy bears to close friends. All this is dominated by the peer phenomenon of making a statement publically about love and friendship.

Other 'special' days such as birthdays and anniversaries have also lead to customized gifts and Indians are definitely tempted to purchase them. Various websites and shops support tailor made gifts such as Mad Over Gifts, Wishpackers, and even leading gift shops such as Archies are becoming a part of this league due to recent high demand. With social media on a roll everything now demands a public display hence more and more people are copying things that their friends are doing.

Besides youth and men, ladies irrespective of their being working, also want to be up to date. Indian housewives indulge in kitty parties where they want to be dressed in high class brands, host lunches at proper multi cuisine restaurants. Career oriented Indian women are also fascinated by fancy cars like Beetle, Porsche etc.; they save money so as to purchase these luxurious items.

India is a soft target for many countries producing different kind of things that can be easily exported here because of India's developing status. The craze of foreign land is quite much here. Indians love to purchase foreign products ranging from agricultural products to luxurious items. International brands have received a warm welcome from Indians such that they have enormously expanding their base here. For example Apple always encounters huge queues and prebooking outside their flagship stores. Also, Indians love spending abroad. Foreign locations have become extremely attractive in India due to the fact that everyone is going. As famous as it is the love India shares for UK and Canada, tourist agencies in India flourish their businesses because of foreign tours demanded by the Indians. The comparison never stops in India for not owning what your acquaintances already have and it is considered quite unacceptable.

Cars have been the first dream of Indian men. Most of them wish to purchase it through their first earning. But a car doesn't have to be just a necessity rather one which makes a statement. Bringing a new car is like bringing a new born baby in Indian families. The car is usually decorated and bought on an auspicious day. Indians can be seen spending exorbitant amount on cars even if its purchase demands a Car Loan or crashing savings. Hence just the right car is brought according to the status of the family. It might be a promotion moving from a scooter or a bike to Tata Nano but usually if it's a second car, hardly any Indian would prefer demotion but a superior one. Also in India word of mouth is one of the biggest source of information and directly affects purchase decisions.

Fashion clothing still tops the list on peer pressure buying. India is comparatively a place which has a huge textile industry of its own. Leading Indian Brands such as Westside, Raymond, Meena Bazaar are doing well along with MNC's such as Levi's Strauss, Tommy Hilfiger etc. but 
guarded by peer pressure Indians are also becoming brand fanatics. Local clothing markets can be found at every corner of the Indian Territory as cloth is a necessity but it's all about brands now.

"And it is not only the socialite crowd that wants to be seen in the snazziest designer brands. I know few college students who refuse to wear anything unbranded. Even if it means a reduction in quantity, young people prefer splurging on one branded commodity," says retailer Deepika Sharma.

Sritha K, a media professional, explains, "It's not a 'status thing', well at least for most, but more of a 'quality thing'. Investing in a good label ensures longevity and a certain air of class. "One of the other findings of the survey was that 63 per cent of Indians want to showcase the latest trend before their friends. "People in our country have a proclivity towards timeless fashion. They don't mind spending a bomb on stuff that they feel will stand the test of time, style and a million washes," says Imran Hussain, brand expert .So, what are the products that Indians absolutely insist be branded? Chaitanya Kumar, a financial consultant, says, "I am particular that my watches are of the best possible make. Next would be shoes and of course, gadgets! I am not fussy when it comes to clothes. "On the other hand, Natasha Abraham, a dancer, states that perfumes top her list. "I'd be mortified if someone caught me using an imitation! Of course, we women are very particular about our clothes, but we give equal weightage to cosmetics, shoes, bags and jewellery"

(http://articles.economictimes.indiatimes.com/2011-07-09/news/29755761_1_brand-financialconsultant-indians)

\section{Conclusion}

In conclusion as a result of this research we have observed that Peers are present all around and everywhere. Their impact on our daily lives can least be ignored. Its influence as a pressure has become a prerequisite for the word itself to hold meaning. It may or may not be perceived positively but its impact on purchase is definitely positive.

Just like any other thing, purchase, consumption and buying cannot undermine the behavioural changes that one faces under peer pressure. It persuades, pushes and multiplies the level and frequency making it act as a catalyst to purchase. Primarily adolescents are considered to be more vulnerable in areas such as tobacco and alcohol purchase and consumption, none the less all age groups feel the peer pressure which is visible through the brand consciousness everywhere. Various host of factors influence a purchase and peer pressure definitely dominates the sub conscious mind!

\section{References}

[1] Shruti Gulati, "Peer Pressure: A catalyst to Purchase" Ijars International Journal of Management \& Corporate Affairs.

[2] Journal of Clinical and Consulting Psychology

[3] http://kidshealth.org/kid/feeling/friend/peer_pressure.html

[4] http://www.sciencedirect.com/science/article/pii/S0022435904000235

[5] http://addictions.about.com/od/howaddictionhappens/f/Peer_Pressure.htm 
[6] https://en.wikipedia.org/wiki/Peer_pressure

[7] The Economic Times

[8] http://dictionary.cambridge.org/dictionary/british/peer-pressure

[9] http://study.com/academy/lesson/what-is-peer-pressure-definition-lesson-quiz.html

[10] http://www.healthofchildren.com/P/Peer-Pressure.html

[11] http://testfunda.com/examprep/mba-resource/user-resources/article/negative-and-positive-effectsof-peer-pressure.htm?assetid=f19d2bf3-6af6-425f-9961-5c613e1a8a60

[12] http://ideas.time.com/2011/10/28/monkey-see-monkey-buy/

[13] http://www.123helpme.com/peer-pressure-and-consumer-behavior-view.asp?id=166811

[14] http://www.cbc.ca/news/canada/peer-pressure-biggest-influence-on-teen-smokers-study-1.342542

[15] http://steinhardt.nyu.edu/opus/issues/2011/fall/peer

[16] https://www.qualvu.com/asynchronous-video-research/9403/

[17] http://www.investopedia.com/financial-edge/1111/5-things-people-buy-because-of-peerpressure.aspx

[18] http://www.thomkesslertherapist.com/2015/04/20/peer-pressure/

[19] http://core.ac.uk/download/pdf/26201995.pdf

[20] http://www.doozyread.com/2013/04/brand-obsession-whats-in-name.html

[21] http://www.indiaparenting.com/teen-issues/154_1279/teenagers-and-peer-pressure.html

[22] http://parentedge.in/common-forms-of-peer-pressure-in-the-indian-scenario/

[23] http://articles.economictimes.indiatimes.com/2011-07-09/news/29755761_1_brand-financialconsultant-indians

[24] http://www.123helpme.com/peer-pressure-and-consumer-behavior-view.asp?id=166811

[25] http://www.huffingtonpost.in/entry/peer-pressure_n_6316702

[26] http://living.thebump.com/peer-pressure-influence-teen-purchasing-choices-8191.html

*Corresponding author.

E-mail address: gulati_shruti@yahoo.co.in 